\title{
Preparation and Freeze-Thaw Resistance of Geopolymer-Based Natural Plant Fiber Composites
}

\author{
Jianli TAN ${ }^{\mathrm{a}, \mathrm{b}}$, Yuantian HUANG ${ }^{\mathrm{a}}$, Leping LIU ${ }^{\mathrm{a}, \mathrm{b}}$, Shujuan YU and Guangjian \\ ZHENG $^{\mathrm{a}, 1}$ \\ ${ }^{a}$ Guangxi Key Laboratory of Natural Polymer Chemistry and Physics, Nanning \\ Normal University, Nanning 530001, China \\ ${ }^{\mathrm{b}}$ Guangxi Key Laboratory of Petrochemical Resource Processing and Process \\ Intensification Technology, Guangxi University, Nanning 530004, China
}

\begin{abstract}
Slag, alkaline activator solution and straw fibers were used to manufacture geopolymer-based natural plant fiber composites. In this study, three influences of water glass modulus, fiber content and water-binder ratio on bending strength were studied by orthogonal experiment and single factor analysis. The results indicate that the order of the factors affecting the bending strength is: waterbinder ratio $>$ fiber content $>$ water glass modulus. When the water-binder ratio is 0.4 , the fiber content is $12 \%$, and the water glass modulus is 1.9 , the bending strength of composite is up to $9.1 \mathrm{MPa}$, which exceeds the standard requirements (9MPa) for qualified products specified in the standard (GB/T 24312-2009). The SEM and appearance of specimens indicate that the geopolymer-based natural plant fiber composites have good freeze-thaw resistance.
\end{abstract}

Keywords. Natural plant fiber composites, orthogonal experiment, bending strength

\section{Introduction}

Geopolymer is an inorganic polymer formed by connecting [ $\left.\mathrm{SiO}_{4}\right]$ tetrahedron and $\left[\mathrm{AlO}_{4}\right]$ tetrahedron [1]. Geopolymer materials have many excellent chemical and physical properties such as high strength, corrosion resistance, fire resistance, impermeability and frost resistance [2]. However, the defects of cracking and brittleness of geopolymers restrict its application $[3,4]$.

As one of the most abundant natural resources in the world, natural plant fiber can modify the tensile, bending strength, and fracture energy of polymeric composites [5]. Recently, natural plant fibers reinforced geopolymer materials begins to gain increasing attention. So far, there have been some research reports on natural fiber reinforced geopolymer composite materials. Roy et al. [6] made the composites of fly ash-based geopolymer reinforced with abaca (Manila hemp) fiber. The bending strength of composites is $5.5 \mathrm{MPa}$ compared to that of a pristine geopolymer $(2.8 \mathrm{MPa})$. Tekin et al. [7] fabricated the zeolitic tuff-marble waste based geopolymer composites reinforced with cotton and viscon fibers respectively. The bending strength of geopolymer

${ }^{1}$ Corresponding Author, Guangjian ZHENG, Guangxi Key Laboratory of Natural Polymer Chemistry and Physics, Nanning Normal University, Nanning 530001, China; Email: zhgj0920@163.com. 
composite is up to $14.9 \mathrm{MPa}$ when the content of viscon fibers was $2 \%$. Silva et al. [8] used sisal fibers to reinforce geopolymer matrix produced from residues of fired clay brick powder. The maximal bending strength of composites with $2 \%$ fiber content was 3.5 $\mathrm{MPa}$, which corresponded to an increment of $360 \%$ in comparison to the unreinforced matrix. Duan et al. [9] manufactured fly ash-based geopolymer composite reinforced with sawdust. The composite with $20 \%$ sawdust content reached highest bending strength of about $12 \mathrm{MPa}$ after 28 days of curing. Moreover, they investigated the frost resistance of the fly ash-slag-metakaolin based geopoymer. After 100 freeze-thaw cycles, the final remaining mass is still greater than $80 \%$. Kim et al. $[10,11]$ prepared the porous slag based geopolymer concrete reinforced with natural jute fibers and latex, and partially replacing natural stone aggregates with coarse blast furnace slag aggregates. They found that the addition of jute fibers had no contribution to the compressive strength, but the target residual compressive strength of samples reinforced with natural jute fibers were over $80 \%$ after 100 freeze-thaw cycles.

However, the above studies have not evaluated the bending strength and microstructure of geopolymer reinforced with natural plant fibers after freeze-thaw cycles. This paper studies the feasibility of developing a green geopolymer particle board that uses slag-based geopolymer as the matrix and straw fibers as the reinforcement. The preparation parameters of specimens were optimized by orthogonal experiment and single factor analysis, and the effect of different fiber contents on freeze-thaw resistance of composites were discussed in this paper. SEM was used to investigate the microstructure and frost resistance of specimens.

\section{Experiment}

The raw materials for preparation of specimens were slag, straw fibers and water glass. Slag was obtained from Beihai Chenggang Mining Co. Ltd., and the main chemical composition of slag was analysis by XRF (table 1). The straw fibers, locally provided in Guangxi, were milled by crusher and sieved to $-20+40$ mesh. The sodium silicate of the raw material had a modulus of 3.3. It was modified using sodium hydroxide and distilled water to obtain alkaline activator solutions with moduli of $1.7,1.8,1.9$ and 2.0, respectively.

The slag and alkaline activator solution are reacted to obtain a geopolymer paste, which is then mixed with straw fibers. The mixed slurry was cast into steel moulds (22.0 $\mathrm{cm} \times 5.0 \mathrm{~cm} \times 1.0 \mathrm{~cm})$. The specimens were cured at $60^{\circ} \mathrm{C}$ for 7 days and then taken out of the moulds. Freeze-thaw cycles tests were conducted to determine the freeze-thaw resistance of geopolymer composites referring to the China National Standard GB/T 50082-2009. The samples were frozen at $-18 \pm 2{ }^{\circ} \mathrm{C}$ and thawed at $5^{\circ} \mathrm{C}$ in water for $2 \mathrm{~h}$, respectively. Each cycle is completed within $4 \mathrm{~h}$ and total 50 freeze-thaw cycles were conducted. The bending strength of samples were measured using a computer control universal tester. The scanning electron micrographs of samples was obtained by SEM to analysis the micro morphology of the samples.

Table 1. The chemical composition of slag.

\begin{tabular}{llllllll}
\hline Composition & $\mathbf{C a O}$ & $\mathbf{S i O}_{2}$ & $\mathbf{A l}_{2} \mathbf{O}_{3}$ & $\mathbf{M g O}$ & $\mathrm{TiO}_{2}$ & $\mathrm{Fe}_{2} \mathrm{O}_{3}$ & Other \\
\hline Wt $(\%)$ & 39.83 & 33.67 & 13.57 & 8.19 & 0.92 & 0.31 & 3.51 \\
\hline
\end{tabular}




\section{Results and Discussion}

\subsection{Design of Orthogonal Experiment Table and Single Factor Analysis}

The orthogonal experiment and single factor analysis were used to study the three influences of water glass modulus, water-binder ratio and fiber content on the bending strengths referring to the method of Wei et al. [12]. The orthogonal experiment table of $\mathrm{L}_{16}\left(4^{3}\right)$ was designed and the results were showed in table 2 . The order of influencing composite material bending strength index was: water-binder ratio $>$ fiber content $>$ water glass modulus, and the optimal parameter combination is $\mathrm{A}_{3} \mathrm{~B}_{2} \mathrm{C}_{2}$. The single factor curves were evaluated based on the results of orthogonal experiments and the results of single factor analysis are shown in figure 1. The bending strengths of the samples under the three experimental parameters showed similar curves, which first increases and then decreases. The maximum bending strength appears when the water-binder ratio is 0.4 , the water glass modulus is 1.9 and the fiber content is $12 \%$ respectively. The highest $7 \mathrm{~d}$ average bending strength of samples can reach $9.1 \mathrm{MPa}$, which is higher than the requirement of China National Standard (GB/T 24312-2009) "Cement Particleboard" qualified products $(\geq 9 \mathrm{MPa})$. This means that the composites prepared in this study may be used in the production of geopolymer-based plant fiberboard in the future.
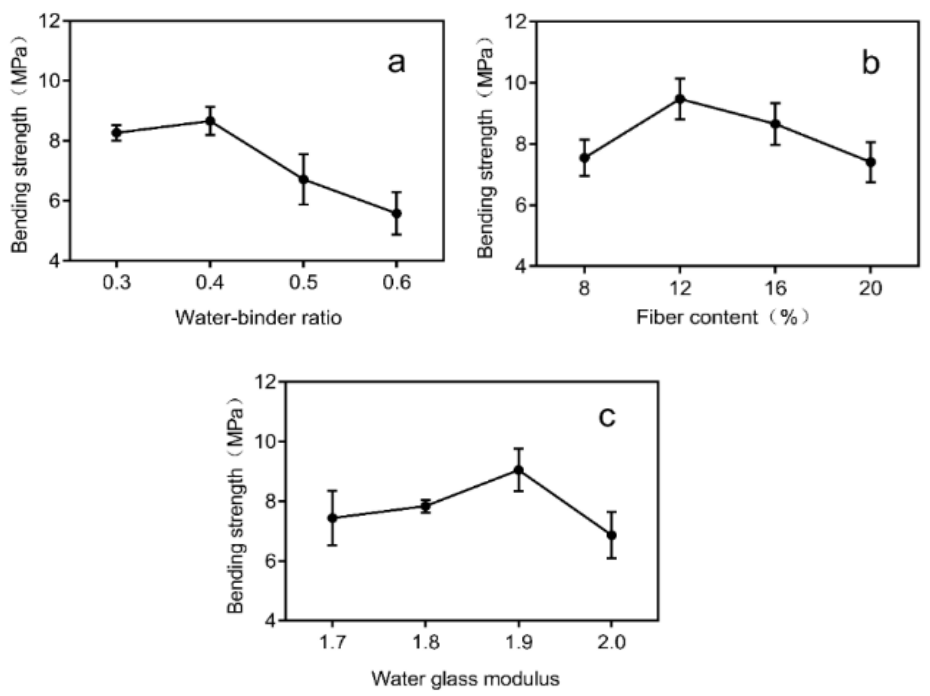

Figure 1. The influence of (a) water-binder ratio, (b) fiber content and (c) water glass modulus on bending strength of samples.

\subsection{Freeze-Thaw Resistance of Specimens}

The influence of plant fiber content on the bending strengths of specimens before and after freeze-thaw is given in figure 2 . The bending strength of the specimens before and after the freeze-thaw increases first and then decreases with the increases of fiber content. The highest bending strengths of the specimen before and after freeze-thaw with $12 \%$ fiber content are 9.1 MPa and 7.0Mpa respectively. The loss rate of the sample's bending strength is $28.2 \%$. It can also be observed that as the fiber content increases, the bending 
strength of the sample decreases faster, especially as the fiber content is $20 \%$, the bending strength of the sample drops from 7.4 MPa before freeze-thaw to $2.5 \mathrm{M}$ Pa after freezethaw. The loss rate of bending strength is $66.3 \%$, which indicates that the fiber content has a great influence on the freeze-thaw results and the increase in fiber content has negative effects on freeze-thaw resistance [13].

Table 2. Different variables and levels correspond to orthogonal array $\mathrm{L}_{16}\left(4^{3}\right)$.

\begin{tabular}{lllll}
\hline $\begin{array}{l}\text { Experimental } \\
\text { number }\end{array}$ & $\begin{array}{l}\text { A } \\
\text { Water glass } \\
\text { modulus }\end{array}$ & $\begin{array}{l}\text { B } \\
\text { Fiber content } \\
(\%)\end{array}$ & $\begin{array}{l}\text { C } \\
\text { Water-binder } \\
\text { ratio }\end{array}$ & $\begin{array}{l}\mathbf{7 d} \text { average bending strength } \\
(\mathbf{M P a})\end{array}$ \\
\hline 1 & 1.7 & 8 & 0.3 & 6.5 \\
2 & 1.7 & 12 & 0.4 & 8.1 \\
3 & 1.7 & 16 & 0.5 & 5.3 \\
4 & 1.7 & 20 & 0.6 & 4.7 \\
5 & 1.8 & 12 & 0.3 & 7.5 \\
\hline 6 & 1.8 & 8 & 0.4 & 7.6 \\
7 & 1.8 & 20 & 0.5 & 6.3 \\
8 & 1.8 & 16 & 0.6 & 6.3 \\
9 & 1.9 & 16 & 0.3 & 6.5 \\
10 & 1.9 & 20 & 0.4 & 7.0 \\
11 & 1.9 & 12 & 0.5 & 7.8 \\
12 & 1.9 & 8 & 0.6 & 4.3 \\
13 & 2.0 & 20 & 0.3 & 5.3 \\
14 & 2.0 & 16 & 0.4 & 8.7 \\
15 & 2.0 & 8 & 0.5 & 6.3 \\
16 & 2.0 & 12 & 0.6 & 6.2 \\
$\mathrm{~K}_{1}$ & 24.6 & 24.7 & 25.8 & \\
$\mathrm{~K}_{2}$ & 27.7 & 29.6 & 31.4 & \\
$\mathrm{~K}_{3}$ & 25.6 & 26.8 & 25.7 & \\
$\mathrm{~K}_{4}$ & 26.5 & 23.3 & 21.5 & \\
$\mathrm{k}_{1}$ & 6.2 & 6.2 & 6.5 & \\
$\mathrm{k}_{2}$ & 6.9 & 7.4 & 7.9 & \\
$\mathrm{k}_{3}$ & 6.4 & 6.7 & 6.4 & \\
$\mathrm{k}_{4}$ & 6.6 & 5.8 & 5.4 & \\
$\mathrm{R}$ & 0.7 & 1.6 & 2.5 & \\
\hline $0 \%$ & & & \\
\hline
\end{tabular}

Order of influencing $\quad \mathrm{C}>\mathrm{B}>\mathrm{A}$

Optimal parameter combination $\mathrm{A}_{3} \mathrm{~B}_{2} \mathrm{C}_{2}$

The fracture surface of specimens before and after freeze-thaw are presented in figure 3 . The fiber in figure $3 \mathrm{a}$ is tightly embedded in the geopolymer matrix, which shows the good fiber-matrix bond. In contrast, it can be observed from figure $3 b$ that there is a large gap between the fiber and the geopolymer matrix, as well as lots of cracks in the matrix, which reveals the debonding between fiber and the geopolymer matrix [14]. A possible reason is that when water penetrates into the matrix, it freezes below freezing temperature and causes the matrix to crack. Then more water will penetrate into the cracks of the matrix in the next freeze-thaw cycle, which can result in more cracks [15]. In addition, the water absorption characteristics of plant fibers will accelerate the above 
process and give rise to the debonding of fiber and the geopolymer matrix.

The appearances of the specimens before and after freeze-thaw are shown in figure 4. There is almost no change on the appearances of the specimen between before and after freeze-thaw, as well as no obvious defects such as missing edges, missing corners and cracks on the surface of the specimen, which indicates that the geopolymer-based plant fiber composites have good freeze-thaw resistance.

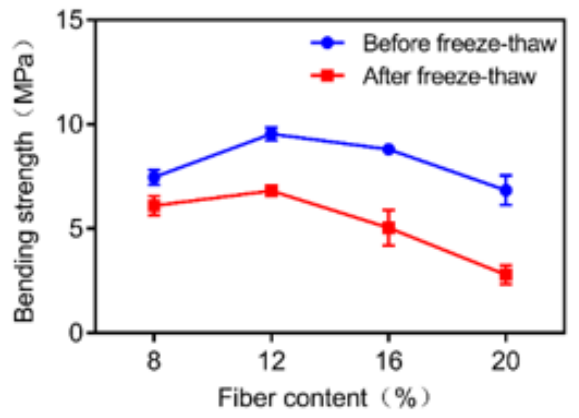

Figure 2. The influence of fiber content on bending strength before and after freeze-thaw.

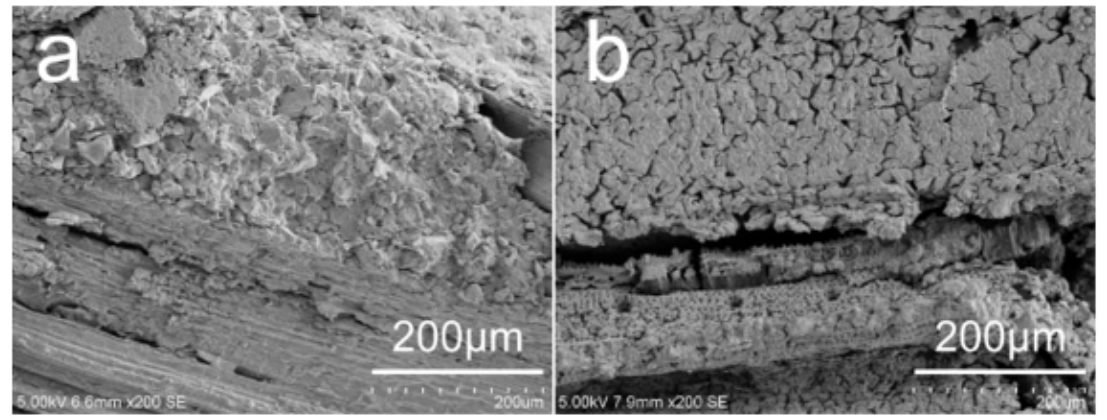

Figure 3. SEM image of specimen fracture (a) before and (b) after freeze-thaw.

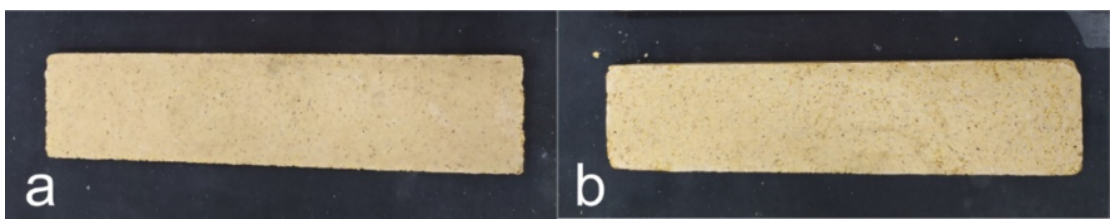

Figure 4. The appearance of specimen (a) before and (b) after freeze-thaw.

\section{Conclusion}

Taking the bending strength of the geopolymer composite materials as the evaluation index, the orthogonal experiment and single factor analysis were used to be obtained optimal parameter combination, which the water-binder ratio is 0.4 , the fiber content $12 \%$ and the water glass modulus 1.9 . The best bending strength $(9.1 \mathrm{MPa})$ of the optimized geopolymer composite material meets the requirement specified by China National Standard (GB/T 24312-2009) "Cement Bonded Particleboard" qualified 
products $(\geq 9 \mathrm{MPa})$. Although SEM observation reveals the debonding between the fiber and the geopolymer matrix after freeze-thaw, intact appearance of the specimens indicates that geopolymer-based plant fiber composites have good freeze-thaw resistance.

\section{Acknowledgement}

This work was supported by National Natural Science Foundation of China (51562002) and the Opening Project of Guangxi Key Laboratory of Petrochemical Resource Processing and Process Intensification Technology(2016K006).

\section{References}

[1] Sumabat A, Maalac A J, Nguyen H T, Kalaw M E and Promentilla M 2015 Optimizing geopolymer-based material for industrial application with analytic hierarchy process and multi-response surface analysis Chem. Eng. Trans. 45 1147-1152.

[2] Zheng G, Cui X, Zhang W and Tong Z 2009 Preparation of geopolymer precursors by sol-gel method and their characterization J. Mater. Sci. 44 (15) 3991-3996.

[3] Zhao Q, Nair B, Rahimian T and Balaguru P 2007 Novel geopolymer based composites with enhanced ductility J. Mater. Sci. 42 (9) 3131-3137.

[4] Ferone C, Roviello G, Colangelo F, Cioffi R and Tarallo O 2013 Novel hybrid organic-geopolymer materials Appl. Clay Sci. 73 (Mar.) 42-50.

[5] Asrani N P, Gunasekaran M, Abdelgader H S, Kathirvel P and Kothandapani K 2019 Investigation on mode I fracture behavior of hybrid fiber-reinforced geopolymer composites Arab. J. Sci. Eng. 44 85458555.

[6] Roy M, Janne N and Michael P 2017 Chemical treatment of waste abaca for natural fiber-reinforced geopolymer composite Mater. 10 (6) 579.

[7] Tekin I, Gencel O, Gholampour A A, Oren O H and Ozbakkaloglu T 2020 Recycling zeolitic tuff and marble waste in the production of eco-friendly geopolymer concretes J. Clean. Prod. 268122298.

[8] Silva G, Kim S, Bertolotti B, Nakamatsu J and Aguilar R 2020 Optimization of a reinforced geopolymer composite using natural fibers and construction wastes Constr. Build. Mater. 258119697.

[9] Duan P, Yan C and Zhou W 2017 A novel water permeable geopolymer with high strength and high permeability coefficient derived from fly ash, slag and metakaolin Adv. Powder Technol. 28 (5) 14301434.

[10] Kim. H and Park C 2016 Plant growth and water purification of porous vegetation concrete formed of blast furnace slag, natural jute fiber and styrene butadiene latex Sustainability 8 (4) 386.

[11] Kim H, Kim C, Jeon J and Park C 2016 Effects on the physical and mechanical properties of porous concrete for plant growth of blast furnace slag, natural jute fiber, and styrene butadiene latex using a dry mixing manufacturing process Mater. 9 (2) 84.

[12] Wei S, Tan J, Lu W, Liu L, Yu S and Zheng G 2018 Preparation and performances of geopolymer-based plant fiber composites Solid State Phenom. 281 266-271.

[13] Soroushian P, Nagi M and Okwuegbu A 1992 Freeze-thaw durability of lightweight carbon fiber reinforced cement composites Aci. Mater. J. 89 491-494.

[14] Azwa Z N, Yousif B F, Manalo A C and Karunasena W 2013 A review on the degradability of polymeric composites based on natural fibres Mater. Design 47 (9) 424-442.

[15] Powers T C 1949 Air requirement of frost-resistant concrete Proceedings of the Highway Research Board Annual Meeting (Washington, D.C.) 29 184-211. 